\title{
Analytical Model for Deflections of Bonded Posttensioned Concrete Slabs
}

\author{
Min Sook Kim, ${ }^{1}$ Joowon Kang, ${ }^{2}$ and Young Hak Lee ${ }^{1}$ \\ ${ }^{1}$ Department of Architectural Engineering, Kyung Hee University, 1732 Deogyeong-daero, Yongin, Republic of Korea \\ ${ }^{2}$ School of Architecture, Yeungnam University, 280 Daehak-ro, Gyeongsan, Republic of Korea
}

Correspondence should be addressed to Young Hak Lee; leeyh@khu.ac.kr

Received 13 December 2016; Accepted 7 February 2017; Published 5 March 2017

Academic Editor: Francesco Caputo

Copyright (C) 2017 Min Sook Kim et al. This is an open access article distributed under the Creative Commons Attribution License, which permits unrestricted use, distribution, and reproduction in any medium, provided the original work is properly cited.

This paper presents a finite element analysis approach to evaluate the flexural behavior of posttensioned two-way slabs depending on the tendon layout. A finite element model was established based on layered and degenerated shell elements. Nonlinearities of the materials are considered using the stress-strain relationships for concrete, reinforcing steel, and prestressing tendons. Flexural testing of the posttensioned two-way slabs was conducted to validate the developed analytical process. Comparing the analytical results with the experimental results in terms of deflections, it showed generally good agreements. Also a parametric study was performed to investigate the effects of different types of tendon layout.

\section{Introduction}

Posttensioned concrete slabs have many advantages, such as rapid construction, reduction of overall member depth, and reduced materials. In addition, posttensioned concrete slabs with proper posttensioning show little deflection and few cracks under service loads. Although posttensioned concrete slabs have many advantages, their performance is still not fully understood, and the behaviors of two-way slab systems are more difficult to determine than those of one-way slabs. To evaluate posttensioned concrete slabs, several experimental studies have been performed. Burns and Hemakom [1] observed the strength and behavior of posttensioned flat plates. They applied the banded tendon layout in column strips in the $\mathrm{x}$-direction and distributed single tendons in the y-direction on the slabs. Through this study they found that the banded and distributed tendon layout improved the flexural and shear capacities. Kosut et al. [2] experimentally evaluated the behavior of posttensioned flat plates with distributed and banded tendon arrangements in each direction. They found that banded tendons on the column strip can resist punching shear failure, and distributed tendons can improve flexural capacity. Roschke and Inoue [3] tested prestressed concrete flat slabs to investigate strain distribution in regions adjacent to the transverse posttensioning bands.

To analyze complex posttensioned concrete slabs efficiently, some researchers have proposed finite element approaches. Van Greunen and Scordelis [4] researched a numerical procedure for the materials and a geometric nonlinear analysis for prestressed concrete slabs. Wu et al. [5] proposed a tendon model based on the finite element method that can represent the interaction between tendons and concrete. They verified the accuracy of their proposed equation against existing experimental data. El-Mezaini and Citipitioğlu [6] developed quadratic and cubic finite elements with movable nodes to predict the behavior of different bond conditions for the tendons. Kang and Huang [7] proposed nonlinear finite element models to evaluate the behavior of unbonded posttensioned slab-column connections. The spring elements and contact formation were applied to the model to consider the interface between the concrete and prestressing tendon. Kang et al. [8] compared the structural performance of the bonded and unbonded posttensioned concrete members through experiment and analysis. Ghallab [9] suggested using simple equations to predict the prestressing tendons at ultimate stage of continuous concrete beams. The simple equations were verified by comparing 
with existing experimental data. Although much analytical research has been performed to evaluate the behavior of bonded and unbonded posttensioned concrete members, a relatively limited number of studies have been reported for the prediction of flexural behavior considering tendon layouts.

Two-way slab systems offer several possible arrangements for the tendon layout [10]: banded, distributed, or a mixed layout. Posttensioned slabs are used for long spans and heavy live loads, so flexural strength and ductility are important. Flexural strength usually governs the behavior of the interior panel in two-way slabs. In other words, the distribution of tendons can affect the flexural behavior and ductility of the interior panel of the two-way slabs. Though many researchers have focused on the development of finite element models, little information is available on the flexural behavior of posttensioned two-way slabs with different tendon layouts. In this study, examined was the flexural behavior of posttensioned two-way slabs depending on the tendon layout.

The objective of this paper is to present an efficient numerical analysis approach for the materials and a geometric nonlinear analysis for the posttensioned two-way slabs. In this study, developed was a nonlinear finite element model that can simulate the behavior of posttensioned two-way slabs. The reinforced concrete was modeled as combination of concrete, steel, and prestressing tendons. The test results were compared with those from the finite element model as well.

\section{Finite Element Model}

2.1. Layered Element Formulation. A finite element model formulated using layered and degenerate shell elements can be used in a three-dimensional global analysis of structures. Eight-node isoparametric degenerated shell elements were formulated following the procedure of Hinton and Owen [11]. It was assumed that plane cross-sections remain both plane and normal during bending. Layered elements were applied to account for the behaviors of the reinforced concrete members, which exhibited different properties in the thickness direction because of the placement of the reinforcements. Each element is divided into layers, and each layer has one integration point on its midsurface. Each layer was composed of different materials; concrete, steel reinforcement, and prestressing tendon are defined separately. The strains and stresses are calculated at midpoint of each layer. The strain-displacement matrix and the constitutive matrix are calculated at the midpoint of each layer. Stress resultants are evaluated by integrating the corresponding stress. Normal forces and bending moments can be obtained by

$$
\begin{aligned}
N_{x(y)} & =\int_{-h / 2}^{h / 2} \sigma_{x(y)} d z=\frac{h}{2} \sum_{i=1}^{n} \sigma_{x(y)}^{i} \Delta \zeta^{i}, \\
M_{x(y)(x y)} & =-\int_{-\frac{h}{2}}^{\frac{h}{2}} \sigma_{x(y)(x y)} z d z \\
& =-\frac{h^{2}}{4} \sum_{i=1}^{n} \sigma_{x(y)\left(\tau_{x y}\right)}^{l} \zeta^{i} \Delta \zeta^{i},
\end{aligned}
$$

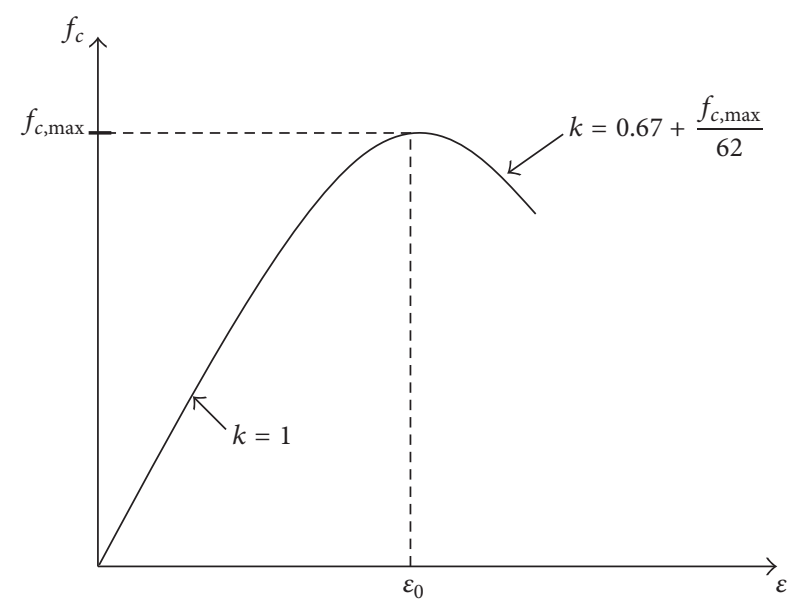

FIGURE 1: Stress-strain relationship in compression by Collins and Porasz (1989).

where $N_{x}$ is normal force, $M_{x}$ is bending moment, $\sigma$ is normal stress, $h$ is layer depth, and $n$ is number of layers.

The reinforcement layers were used to model the in-plane reinforcement. Transverse reinforcement can be specified as a property of a concrete layer. The prestressing tendons at a single depth were grouped with the same prestressing force into one layer [12]. The concrete, steel reinforcement, and prestressing tendons were assumed to be perfectly bonded. The perfect bond is applicable to the analysis of reinforced concrete and posttensioned concrete with bonded tendons. The same degrees of freedom were assigned to concrete and reinforcement nodes occupying a single location.

2.2. Constitutive Models. In this paper, the failure of concrete two-way slabs is considered to be tension cracking or plastic yielding of reinforcement. Uncracked concrete was assumed to be a linear elastic material. After cracking, the concrete was treated as an orthotropic material. The total material matrix consists of concrete, steel reinforcement, and prestressing tendons.

Figure 1 shows the stress-strain relationship for concrete in compression [13]. The compressive stress of concrete can be calculated by

$$
\begin{aligned}
f_{c} & =\frac{f_{c 2, \max }\left(n \varepsilon / \varepsilon_{c}^{\prime}\right)}{(n-1)+\left(\varepsilon / \varepsilon_{c}^{\prime}\right)^{n k}}, \\
f_{c, \text { max }} & =\frac{f_{c}^{\prime}}{0.8-0.34\left(\varepsilon_{c} / \varepsilon_{c}^{\prime}\right)} \leq f_{c}^{\prime}, \\
n & =0.8+\frac{f_{c 2, \max }}{17},
\end{aligned}
$$

where $f_{c}$ is the concrete stress; $f_{c 2 \text {, max }}$ is the compressive stress of cracked concrete; $\varepsilon_{c}$ is the concrete strain; $\varepsilon_{c}^{\prime}$ is the concrete strain corresponding to peak compressive stress; and $f_{c}^{\prime}$ is the compressive cylinder strength of concrete.

After cracking, the stiffness of the reinforced concrete decreases, but it does not drop to zero because the intact 


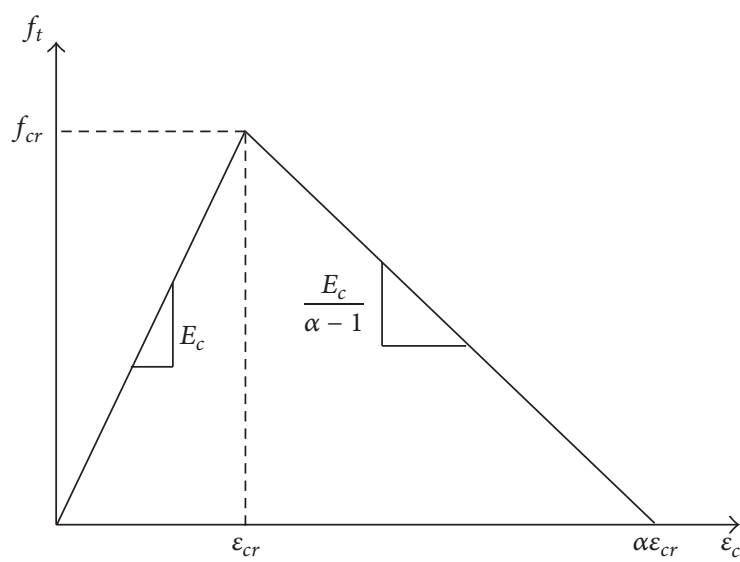

FIgURE 2: Average stress-strain relationship proposed by Lin and Scordelis (1975).

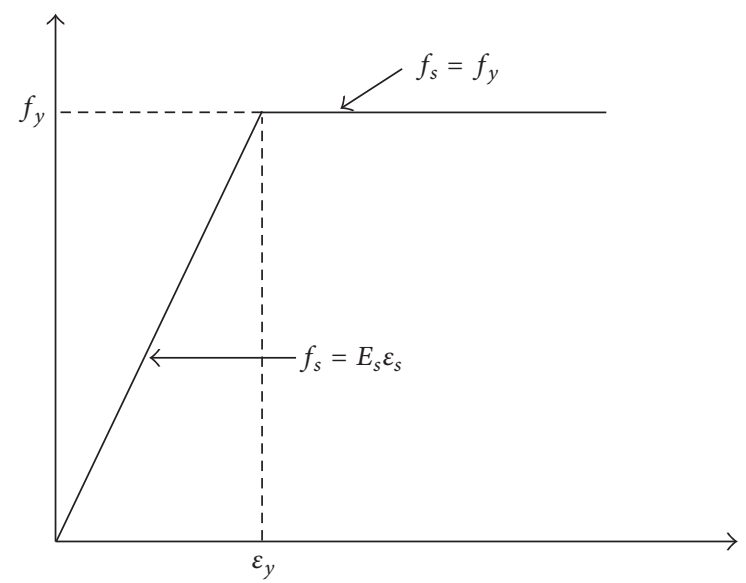

FIGURE 3: Stress-strain relationship of steel reinforcement.

concrete between adjacent cracks can still carry some tensile stress due to the bond between the reinforcement and surrounding concrete. In this paper, tension stiffening was modeled as a constitutive model [14], as shown in Figure 2.

The steel reinforcement was considered as steel layers with uniaxial behavior. A bilinear model was adopted for the elastoplastic stress-strain relationship, as shown in Figure 3. The stress-strain relationship was characterized by Young's modulus $E_{s}$ and the uniaxial yield stress $f_{y}$.

For the prestressing tendon, Menegotto and Pinto's model [15] was adopted (Figure 4). The mathematical expression is given as follows:

$$
\begin{aligned}
\sigma_{p} & =E_{p} \varepsilon_{P}\left[Q+\frac{1-Q}{\left[1+\left(E_{p} \varepsilon_{p} / K f_{p y}\right)^{N}\right]^{1 / N}}\right], \\
Q & =\frac{f_{p u}-K f_{p y}}{E_{p} \varepsilon_{p u}-K f_{p y}},
\end{aligned}
$$

where $\sigma_{p}$ is the stress of a prestressing tendon; $E_{p}$ is Young's modulus of the prestressing tendon; $\varepsilon_{p}$ is the strain of the

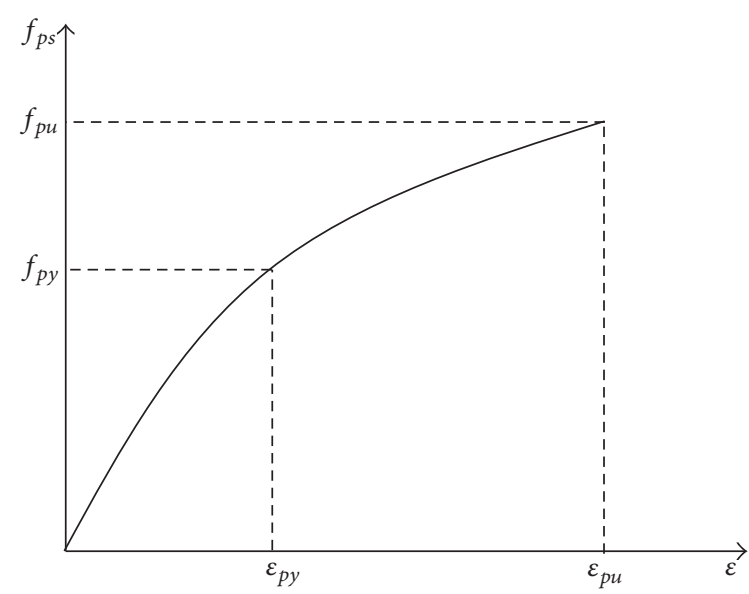

FIGURE 4: Constitutive model of prestressing tendon proposed by Menegotto and Pinto (1973).

prestressing tendon; $f_{p y}$ is the yield stress; $f_{p u}$ is the ultimate yield stress; $\varepsilon_{c u}$ is the ultimate strain; and $N, K$, and $Q$ are empirical parameters whose values were recommended by Naaman [16] as $6.06,1.0325$, and 0.00625 , respectively.

2.3. Analysis Procedures. Direct method is applied as solution algorithm [11]. In each iterative step, the full load is applied to the structures. The obtained unknowns are the full displacements. In the first iteration, the materials have linearly elastic behavior and the initial displacements are zero. After that, the model can calculate the new stiffness matrix considering the appropriate material constitutive models. Full load is reapplied to the model, then the stiffness matrix is updated, and displacement can be found. The steps of evaluation and update of stiffness matrix are repeated until the satisfied convergence condition.

The displacement criterion was selected as the convergence condition. The displacement convergence is as follows:

$$
\sqrt{\frac{\sum\left(D_{a}-D_{p}\right)^{2}}{\Sigma D_{a}^{2}}} \times 100 \%<T,
$$

where $D_{a}$ is current step displacement, $D_{p}$ is previous step displacement, and $T$ is tolerance.

Large tolerance value can lead to inaccurate results, and the tolerance was set to 0.8 .

\section{Experimental Program}

To validate the suggested finite element model, flexural testing was performed. The designed compressive strength of the concrete used for the fabrication of the specimens was $35 \mathrm{MPa}$. The average compressive strength measured at 28 days was 36.7 MPa. Deformed steel bars with a diameter of $13 \mathrm{~mm}$ and $10 \mathrm{~mm}$ were used for longitudinal reinforcements and stirrups, respectively. Their tensile strength and modulus of elasticity were $400 \mathrm{MPa}$ and $200 \mathrm{GPa}$, respectively. Seven wire steel-strand tendons with $12.7 \mathrm{~mm}$ of diameter were used. Their nominal ultimate tensile strength was $1860 \mathrm{MPa}$. 


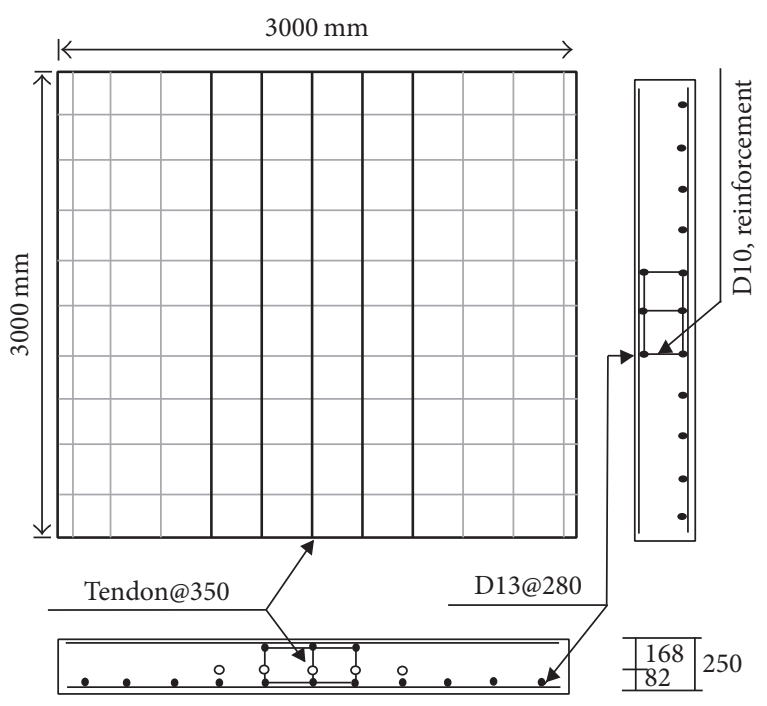

(a) PT-x specimen

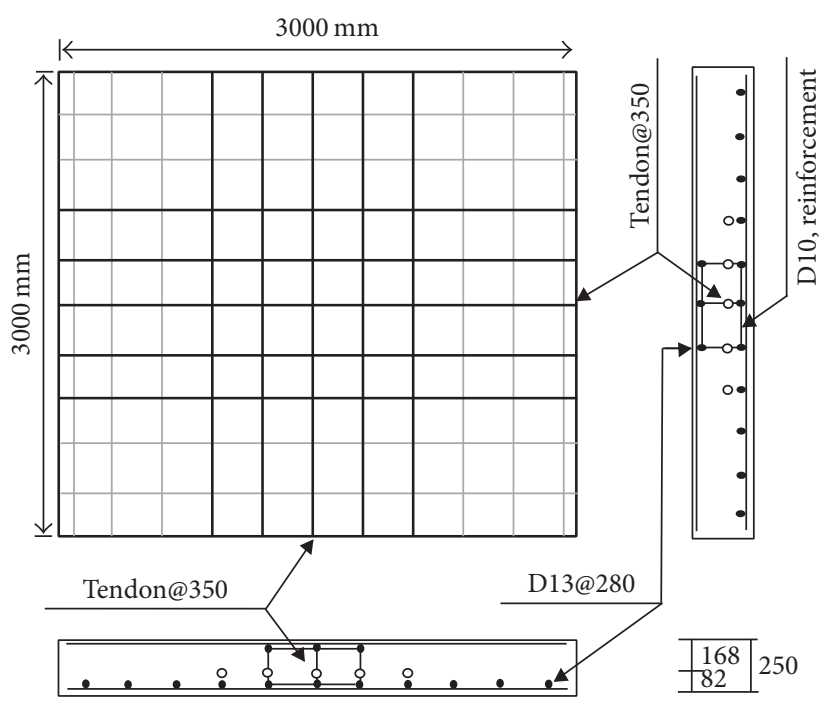

(b) PT-xy specimen

FIGURE 5: Details of the specimens.

TABLE 1: Details of specimens.

\begin{tabular}{lcccccccccc}
\hline Specimen & $A_{s, x}\left(\mathrm{~mm}^{2}\right)$ & $A_{s, y}\left(\mathrm{~mm}^{2}\right)$ & $f_{p e}(\mathrm{MPa})$ & $f_{p e} / f_{p u}$ & $\rho_{p, x}(\%)$ & $\rho_{p, y}(\%)$ & $\rho_{s, x}(\%)$ & $\rho_{s, y}(\%)$ & $d_{p}(\mathrm{~mm})$ & $f_{c}^{\prime}(\mathrm{MPa})$ \\
\hline PT-x & 493.5 & - & 1488 & 0.8 & 0.198 & - & 0.185 & 0.185 & 168 & 36.7 \\
PT-xy & 493.5 & 493.5 & 1488 & 0.8 & 0.198 & 0.198 & 0.185 & 0.185 & 168 & \\
\hline
\end{tabular}

Two posttensioned two-way slabs were manufactured for the test. One specimen had tendons distributed in only the $\mathrm{x}$-direction (PT-x), and the other had tendons distributed in both the $\mathrm{x}$ - and $\mathrm{y}$-directions (PT-xy). Details of the specimens are presented in Figure 5 and summarized in Table 1 . The size of the test specimens was $3000 \mathrm{~mm} \times 3000 \mathrm{~mm}$ with $250 \mathrm{~mm}$ thickness. Both specimens were posttensioned with a constant eccentricity of $43 \mathrm{~mm}$. A prestressing force of $1488 \mathrm{MPa}$ was applied corresponding to approximately $80 \%$ of the tensile strength of the tendon.

Load was applied to each specimen using a hydraulic jack with maximum capacity of $5000 \mathrm{kN}$. The test specimens were simply supported along the four sides. The force generated by the hydraulic jack was transmitted to a loading plate placed at the middle of the specimen. The distance from support to loading point was $1.25 \mathrm{~m}$, giving a shear span to depth ratio of 6.

\section{Numerical Modeling and Discussion}

In order to evaluate the accuracy of the analytical model, the theoretical value is compared with test results. Comparison is made in terms of load-deflections curves. The analytical model size was set to match the posttensioned specimens, and the model contained 100 elements. It was divided into nine layers in the direction of different thickness. The thicknesses of the first and last layers were determined by considering the concrete cover. The steel reinforcements were placed at the 2 nd and 8 th layers in the direction of the thickness. The prestressing tendons were placed at the 6th layer in the direction of the thickness. In this paper, Young's modulus of concrete $\left(E_{c}\right)$ was determined according to ACI 318 [17]. Poisson's coefficient $(\nu)$ is 0.15 , and the equation to compute the modulus of rupture of concrete is $0.32 \sqrt{f_{c}^{\prime}}$ (Table 2). To simulate the experimental support conditions, four sides of slabs are simply supported and the load is applied to the center of the slab.

The model values were compared with load-displacement curves obtained from the posttensioned two-way slabs under flexural loads. The comparisons between the test results and the analytical results are shown in Figures 6 and 7. As shown in the Figures, both test and analytical results indicated that the load-displacement curves exhibit three stages: elastic, cracking, and plastic. Overall, the analytical model predicted the deflection of the posttensioned specimens in a relatively accurate manner. However, in all cases the models show a slightly stiffer response at the cracking stage because prestressing loss and slip were not considered in the finite element analysis. Both the testing and analytical results showed that the one-way and two-way prestressing tendon layout did not significantly affect the maximum load capacity and deflection.

The validated finite element model was used to investigate the effects of changes in span length, height, and concrete strength. In total, nine posttensioned slabs were analyzed as shown in Table 3 . To perform the parametric analysis, the same geometry and material properties were used same as in the verification of the proposed model, along with the one-way tendon layout. The same load to each model was 
TABLE 2: Material properties used in the finite element analysis.

\begin{tabular}{lccccccc}
\hline & & Concrete & & \multicolumn{3}{c}{ Steel and prestressing tendon } \\
$f_{c}^{\prime}(\mathrm{MPa})$ & $f_{t}(\mathrm{MPa})$ & $E_{c}(\mathrm{MPa})$ & $\varepsilon_{c r}$ & $v_{c}$ & $f_{y}(\mathrm{MPa})$ & $E_{s}(\mathrm{GPa})$ & $\nu_{s}$ \\
\hline 36.7 & 3.8 & 28472.9 & 0.002 & 0.15 & 360 & 210 & 0.25 \\
\hline
\end{tabular}

TABLE 3: Analytical dimensions and results of parametric study.

\begin{tabular}{lcccc}
\hline Model & $\begin{array}{c}\text { Span } \\
(\mathrm{mm})\end{array}$ & $\begin{array}{c}\text { Height } \\
(\mathrm{mm})\end{array}$ & $\begin{array}{c}\text { Compressive strength of concrete } \\
(\mathrm{MPa})\end{array}$ & $\begin{array}{c}\text { Displacement } \\
(\mathrm{mm})\end{array}$ \\
\hline PT1 & 3000 & 250 & 35 & 41.77 \\
PT2 & 4500 & 250 & 35 & 48.54 \\
PT3 & 250 & 35 & 56.13 \\
PT4 & 6000 & 250 & 35 & 67.20 \\
PT5 & 7500 & 180 & 35 & 43.62 \\
PT6 & 3000 & 350 & 35 & 40.14 \\
PT7 & 3000 & 450 & 35 & 37.32 \\
PT8 & 3000 & 250 & 50 & 40.33 \\
PT9 & 3000 & 250 & & 38.16 \\
\hline
\end{tabular}

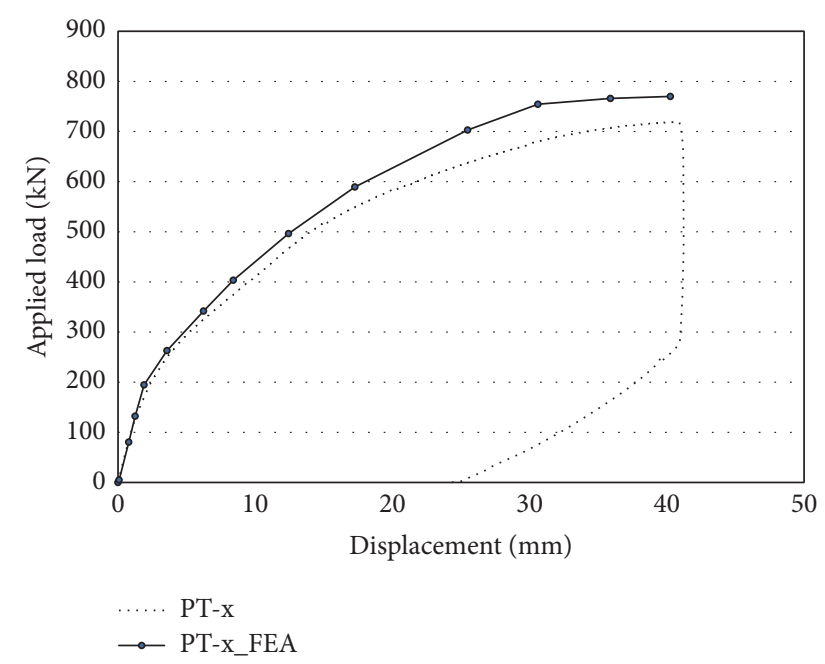

FIgUre 6: Load-displacement relations of PT-x specimen.

applied and compared the results in terms of deflections. Figure 8-10 show the displacement according to span length, slab height, and the compressive strength of the concrete. The displacement increased with the span length and decreased as the height and concrete strength increased. The results of the parametric analysis indicate that the deflection of posttensioned two-way slab is more affected by the span length than by the other variables.

\section{Conclusions}

In this paper, the flexural behavior of posttensioned concrete two-way slab was analytically investigated. A finite element analysis model was proposed to predict the flexural behavior of specimens depending on the tendon layout and conducted flexural tests to evaluate the validity and applicability of the

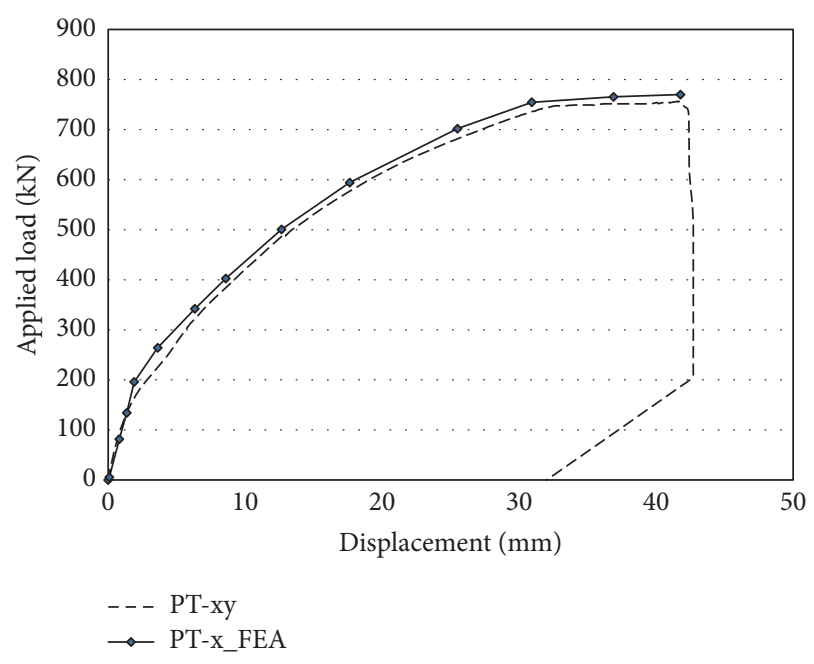

Figure 7: Load-displacement relations of PT-xy specimen.

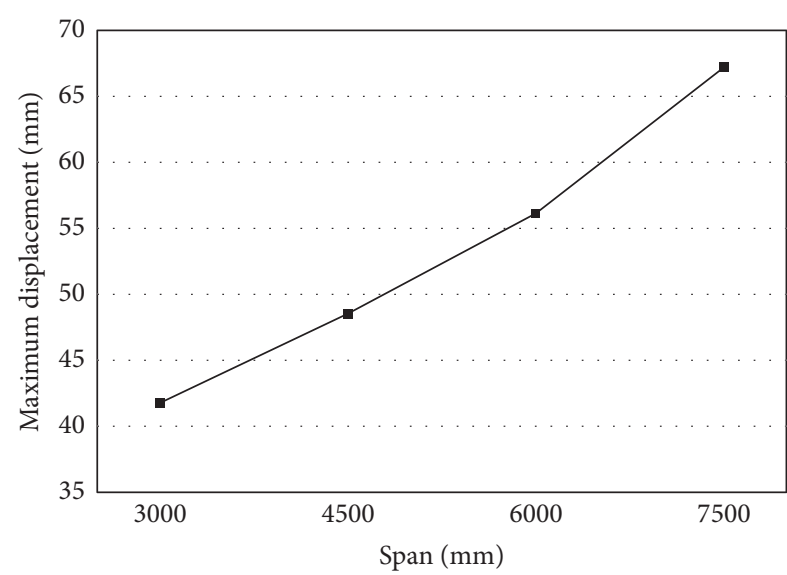

Figure 8: Effect of span length on displacement. 


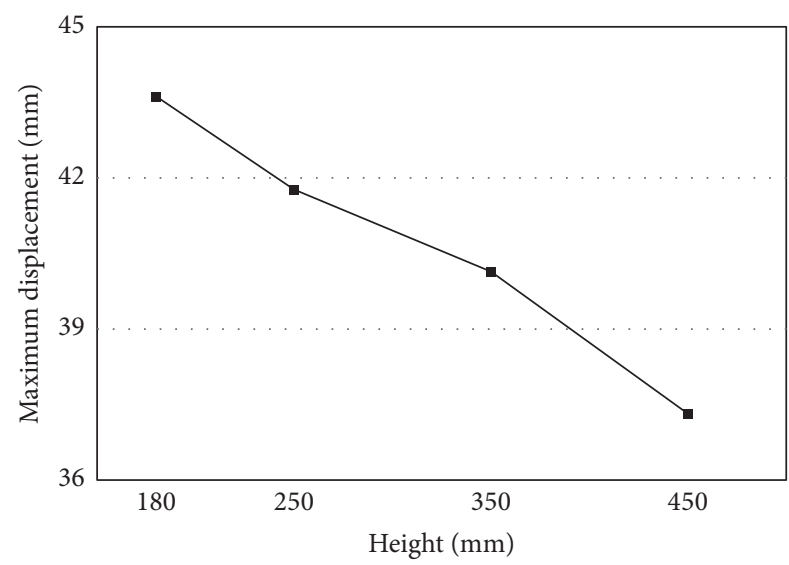

FIGURE 9: Effect of height of slabs on displacement.

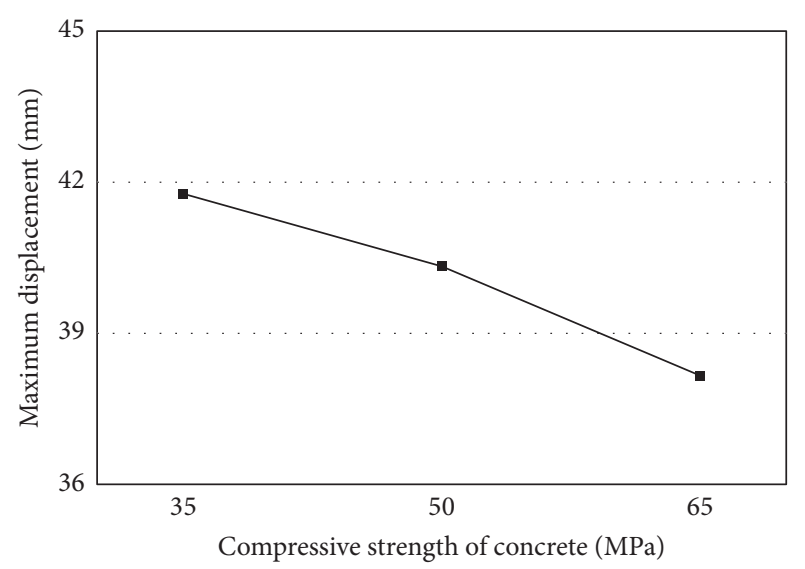

FIGURE 10: Effect of compressive strength of concrete on displacement.

proposed model. The following specific conclusions were drawn from this study:

(1) A finite element analysis model has been developed to evaluate the flexural behavior of posttensioned twoway slabs considering tendon layout. The proposed finite element model, which considers the nonlinear behavior of concrete and reinforcement and neglects the bond slip and loss of prestressing force, gives relatively good predictions for the load-deflection curves.

(2) The increase in the maximum load capacity was unaffected by tendon layouts. Regardless of the direction of the tendon, the load-displacement curves indicated similar responses. The analytical response is slightly stiffer than the test results at the cracking stages, possibly because of bond slip and the loss of prestressing force. Consideration of bond slip and the loss of prestressing force could improve the model accuracy. However, the difference in deflection between the analytical and test results is relatively small. The proposed finite element analysis demonstrates the rationality of the posttensioning two-way slabs model.

(3) To investigate the effects of span length, slab height, and concrete strength on posttensioned two-way slabs, a parametric study was conducted. The displacement increased with the span length and decreased as the concrete strength and member height increased. The span length, height, and concrete strength all contribute to the flexural strength.

\section{Competing Interests}

The authors declare that they have no competing interests.

\section{Acknowledgments}

This work was supported by a National Research Foundation of Korea (NRF) grant funded by the Korean Government (MSIP) (NRF-2013R1A2A2A01067754).

\section{References}

[1] N. H. Burns and R. Hemakom, "Test of post-tensioned flat plate with banded tendons," Journal of Structural Engineering, vol. 111, no. 9, pp. 1899-1915, 1985.

[2] G. M. Kosut, N. H. Burns, and C. V. Winter, "Test of four-panel post-tensioned flat plate," Journal of Structural Engineering, vol. 111, no. 9, pp. 1916-1929, 1985.

[3] P. N. Roschke and M. Inoue, "Effects of banded post-tensioning in prestressed concrete flat slab," Journal of Structural Engineering, vol. 117, no. 2, pp. 563-583, 1991.

[4] J. Van Greunen and A. C. Scordelis, "Nonlinear analysis of prestressed concrete slabs," Journal of Structural Engineering, vol. 109, no. 7, pp. 1742-1760, 1983.

[5] X.-H. Wu, S. Otani, and H. Shiohara, "Tendon model for nonlinear analysis of prestressed concrete structures," Journal of Structural Engineering, vol. 127, no. 4, pp. 398-405, 2001.

[6] N. El-Mezaini and E. Çitipitioğlu, "Finite element analysis of prestressed and reinforced concrete structures," Journal of Structural Engineering, vol. 117, no. 10, pp. 2851-2864, 1991.

[7] T. H. K. Kang and Y. Huang, "Nonlinear finite element analyses of unbonded post-tensioned slab-column connections," PTI Journal, vol. 8, no. 1, pp. 4-19, 2012.

[8] T. H.-K. Kang, Y. Huang, M. Shin, J. D. Lee, and A. S. Cho, "Experimental and numerical assessment of bonded and unbonded post-tensioned concrete members," ACI Structural Journal, vol. 112, no. 6, pp. 735-748, 2015.

[9] A. Ghallab, "Calculating ultimate tendon stress in externally prestressed continuous concrete beams using simplified formulas," Engineering Structures, vol. 46, pp. 417-430, 2013.

[10] B. O. Alami, "Layout of post-tensioning and passive reinforcement in floor slabs," PTI Technical Notes 8, 1999.

[11] E. Hinton and D. R. J. Owen, Finite Element Software for Plates and Shells, Pineridge Press, Swansea, UK, 1984.

[12] J. Chern, C. You, and Z. P. Bazant, "Deformation of progressively cracking partially prestressed concrete beams," PCI Journal, vol. 37, no. 1, pp. 74-85, 1992.

[13] M. P. Collins and A. Porasz, "Shear design for high strength concrete," in Proceeding of the Workshop on Design Aspects of High Strength Concrete, pp. 75-83, 1989. 
[14] C.-S. Lin and A. C. Scordelis, "Nonlinear analysis of rc shells of general form," Journal of the Structural Division, vol. 101, no. 3, pp. 523-538, 1975.

[15] M. Menegotto and P. E. Pinto, "Method of analysis for cyclically loaded R. C. Plane frames, including changes in geometry and non-elastic behavior of elements under combined normal force and bending," in Proceedings of the IABSE Symposium on Resistance and Ultimate Deformability of Structures Acted on by Well-Defined Repeated Loads, pp. 15-22, Lisbon, Portugal, 1973.

[16] A. E. Naaman, "A new methodology for the analysis of beams prestressed with external or unbonded tendons," External Prestressing in Bridges ACI SP120-16, American Concrete Institute, Detroit, Mich, USA, 1990.

[17] American Concrete Institute (ACI), "Building code requirement for reinforced concrete and commentary," ACI 318-14, American Concrete Institute (ACI), Farmington Hills, Mich, USA, 2014. 

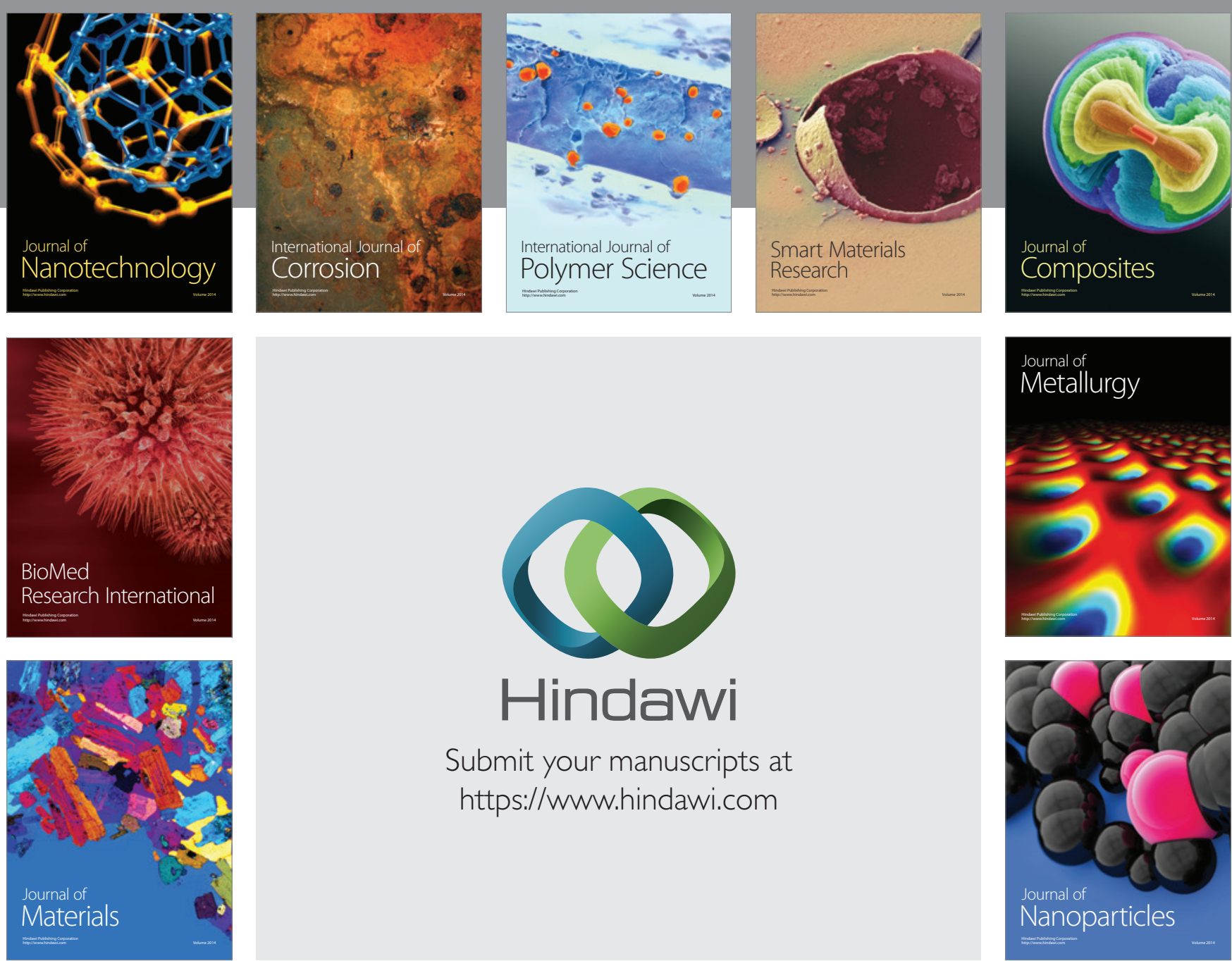

\section{Hindawi}

Submit your manuscripts at

https://www.hindawi.com

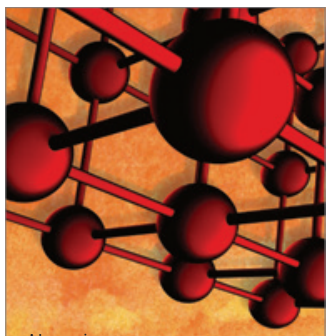

Materials Science and Engineering
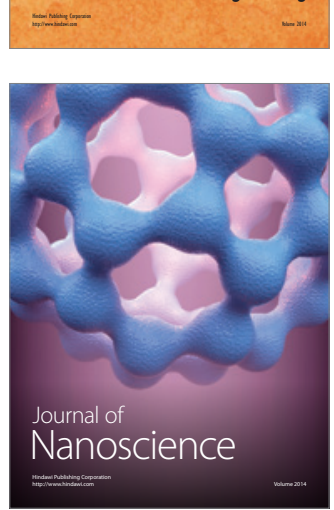
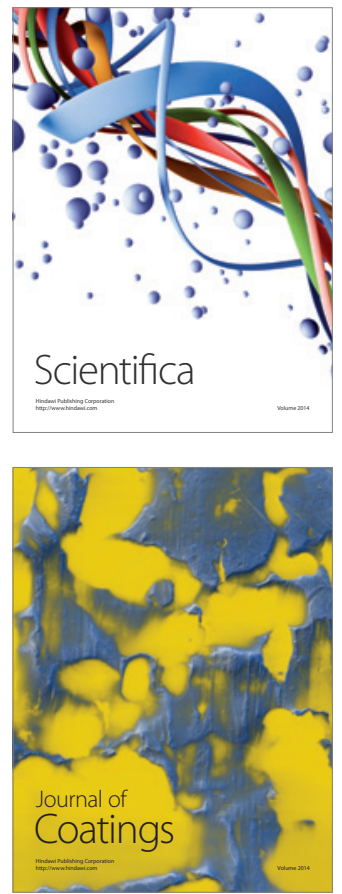
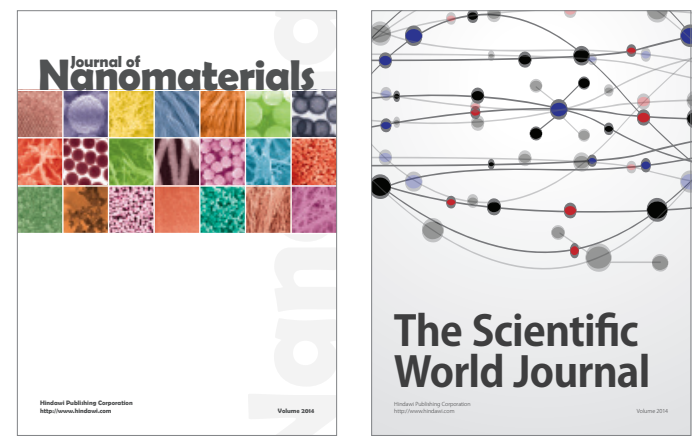

The Scientific World Journal
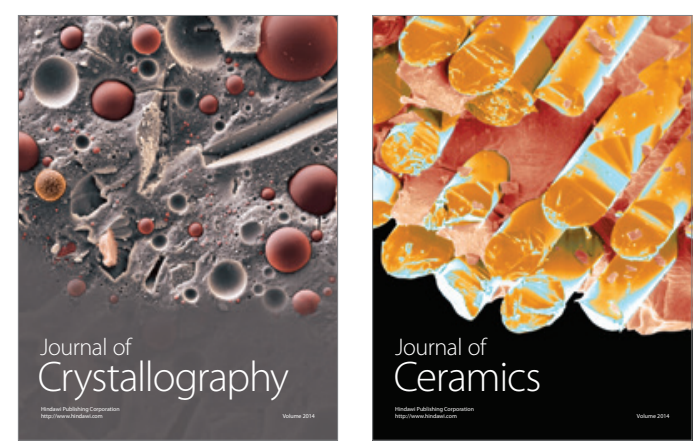
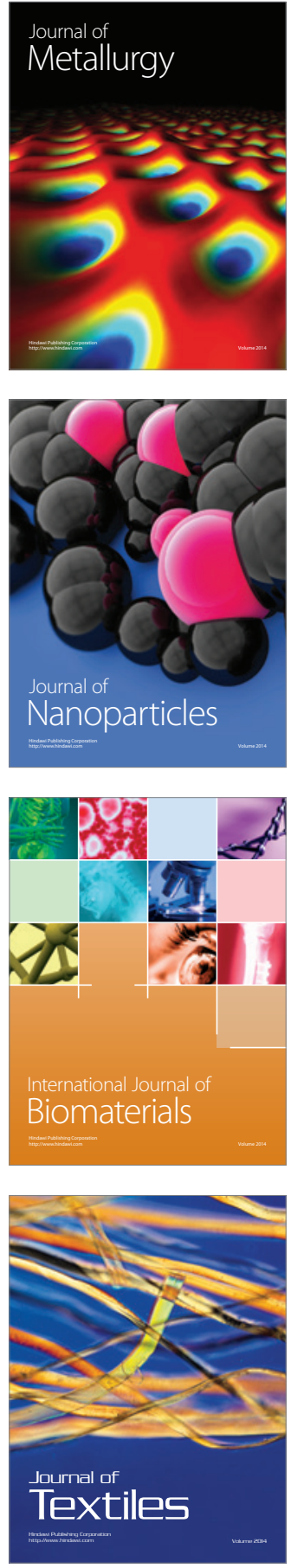